\title{
FORMAÇÃO DE AGENTES COMUNITÁRIOS EM AMBIENTE E SAÚDE NA COLÔNIA JULIANO MOREIRA: UMA ABORDAGEM ETNOGRÁFICA
}

\author{
TRAINING COMMUNITY WORKERS IN ENVIRONMENT AND HEALTH AT THE JULIANO MOREIRA \\ COLONY: AN ETHNOGRAPHIC APPROACH
}

\author{
Fátima Cecchetto ${ }^{1}$ \\ Simone Monteiro ${ }^{2}$ \\ Erica Fernandes ${ }^{3}$
}

Resumo $\mathrm{O}$ trabalho analisa o processo de formação de agentes comunitários em saúde em uma comunidade na zona oeste do Rio de Janeiro, realizada no âmbito de um projeto de construção de metodologias participativas em saúde. A partir da observação etnográfica das práticas comunitárias e educativas e do uso de questionários, o estudo objetivou contextualizar o desenvolvimento do curso e analisar a visão dos participantes sobre as expectativas e aprendizagem de conhecimentos em saúde e ambiente. Os dados revelam que o curso atendeu a parte das expectativas dos alunos e resultou no fortalecimento das redes comunitárias locais e do capital social de alguns participantes. O artigo pretende colaborar para uma antropologia das ações educativas, desenvolvidas em espaços formais e não formais, tanto no âmbito da contextualização da formulação e desenvolvimento de tais ações quanto no da visão dos diferentes atores envolvidos nos programas educativos.

Palavras-chave agentes comunitários; etnografia; ensino em saúde; ambiente; formação de agentes.
Abstract The article analyzes the process of training community health agents in a community in the western zone of Rio de Janeiro, carried out under a project designed to build participatory approaches in health. Based on the ethnographic observation of community and educational practices and by using questionnaires, the study aimed to contextualize the development of the course and analyze the participants' view about the expectations and learning of knowledge on health and the environment. The data show that the course met part of the students' expectations and resulted in the strengthening of local community networks and in some of the participants' social capital. The article aims to contribute to an anthropology of the educational activities, undertaken in formal and informal spaces, both within the context of the formulation and development of such actions and in the vision of the different players involved in the educational programs.

Keywords community workers; ethnography; health education; environment; agent training. 


\section{Introdução}

Este artigo analisa a implementação de um curso de formação de agentes comunitários em saúde e ambiente com moradores da antiga Colônia Juliano Moreira (CJM), no município do Rio de Janeiro, um hospital psiquiátrico desativado no início dos anos 1980 (Fiocruz, 2005). O curso foi promovido pela Fundação Oswaldo Cruz (Fiocruz) no âmbito do projeto "Construção de Metodologias Participativas em Saúde da comunidade no campus da Fiocruz-Jacarepaguá na Zona Oeste do Rio de Janeiro" (Barbosa, 2004). Partindo da observação etnográfica das atividades educativas e da aplicação de um questionário, o estudo teve como propósito analisar as percepções dos alunos, focalizando suas expectativas pessoais e profissionais e visão sobre os temas ministrados. Não foram privilegiados o exame dos pressupostos teórico-metodológicos do curso, tampouco a visão dos professores. Lançamos mão do arcabouço dos estudos antropológicos, como referencial teórico e metodológico para compreender o processo de construção do curso, os aspectos culturais da localidade e do cotidiano dos moradores.

O emprego do conhecimento antropológico para analisar os efeitos de projetos sociais na área da educação, da cultura e da saúde tem sido defendido por pesquisadores das ciências sociais e da educação (Zaluar, 1994; Novaes, 1997; Gazzinelli, 2005; Andre, 2007). Segundo esse eixo de análise, as abordagens qualitativas podem favorecer o entendimento sobre a diversidade, os interesses e as demandas dos atores envolvidos no processo interventivo, sem apagar a alteridade, ou seja, a diferença cultural. O método etnográfico permite focalizar o aspecto dialógico da intervenção, isto é, a polifonia de vozes dos sujeitos que são o objeto dos programas sociais e dos que os formulam. Trata-se de utilizar a abordagem etnográfica, conforme argumenta Clifford Geertz (1989), para realizar uma 'descrição densa' dos significados que podem ser lidos numa ação, permitindo entender as vinculações das diferentes percepções e atitudes políticas dos atores.

Neste trabalho, buscou-se cotejar os vários discursos e representações em torno da proposta institucional com o intuito de tornar possível uma interpretação mais ampla sobre os sentidos atribuídos às ações, evitando considerar somente a visão dos planejadores e executores das políticas ou a do grupo-alvo. Tal perspectiva já foi adotada em estudo anterior (Monteiro e Cecchetto, 2006) centrado na análise da repercussão de programas sociais com jovens. Nesse sentido, pretende-se propor uma metodologia que complemente as avaliações de projetos sociais, domínio que, por vezes, se limita ao uso de modelos quantitativos para aferição de resultados, conforme salientado por Minayo (2005) e Bosi e Mercado (2006).

Inicialmente, são apresentados os aspectos históricos e socioambientais da Colônia Juliano Moreira e uma breve descrição da incorporação da área 
pela Fiocruz. A partir dessa contextualização, o trabalho examina o processo de construção do curso de agentes comunitários em ambiente e saúde. Em seguida, o artigo focaliza os resultados da etnografia das práticas educativas e comunitárias e da visão dos alunos, bem como as reflexões sobre as frentes abertas pela abordagem metodológica utilizada no estudo.

\section{Contextualização sócio-histórica da Colônia}

O estudo foi realizado na área da antiga Colônia Juliano Moreira, que durante 80 anos abrigou um complexo psiquiátrico na zona oeste do município do Rio de Janeiro. No período de execução da pesquisa, residiam nesta região famílias de ex-funcionários do hospital que, em meados do século passado, foram autorizados a ocupar certos espaços como garantia de proximidade do local de trabalho. Apesar da desativação dos serviços hospitalares, as famílias que permaneceram na CJM deram continuidade ao processo de ocupação da área, expandindo suas moradias ou cedendo lotes para pessoas de fora. Nesse processo, muitos obtiveram suas casas por meio da chamada transferência de titularidade, por hereditariedade ou compra, apesar das proibições expressas da direção do campus. Em 2003, a Colônia contava com 220 famílias distribuídas por seis microáreas, com variações de renda e escolaridade (Iser/Fiocruz, 2004).

A pesquisa etnográfica indicou que a CJM pode ser vista como uma espécie de 'antiga comunidade' (Bauman, 2003), uma localidade composta de indivíduos e famílias que reconhecem os mesmos marcos históricos do local, da população e de seus modos de vida. Nas falas dos moradores, são valorizados os laços de vizinhança para a criação dos filhos; a unidade de referência são as redes familiares e de vizinhança e não o indivíduo (Duarte et al., 1993).

Apesar da precariedade de saneamento básico, coleta de lixo, iluminação e transporte público, os moradores das comunidades não são classificados e nem se veem como habitantes de favela. A 'qualidade de vida' do lugar - noção evocada pelos moradores em função da presença da floresta, das cachoeiras e rios, do cultivo de árvores frutíferas e hortas - se traduz como uma marca de distinção social para este grupo. Ademais, como uma área federal e restrita, a Colônia goza de condições próprias de administração e segurança. Neste ponto, sobressai o valor positivo do lugar pela sociabilidade pacífica, que se distingue de outras áreas da cidade pela ausência de assaltos, de tráfico de drogas e, principalmente, dos confrontos armados entre grupos criminosos e a polícia.

Uma outra característica peculiar desse grupo se refere à luta contra o estereótipo de invasores de terras públicas. Uma das tentativas dos moradores de enfrentamento desse estigma foi a apresentação de si como agentes 
preservadores da natureza. Tal argumento permeou as negociações entre os moradores e os novos representantes institucionais em torno da solução para a permanência da população no local. O foco das negociações foi centrado na busca de um consenso operacional de modo que a arena de diálogo entre as partes fosse mantida. Como resultado desse jogo de interações, foi acordado o desenvolvimento de ações educativas sobre parasitologia, que resultaram na proposta de realização do Curso de Formação de Agentes Comunitários, dentre outras ações citadas no próximo item. De acordo com algumas lideranças comunitárias, esta teria sido uma iniciativa da Fiocruz de manter uma política de 'boa vizinhança', ou seja, valer-se de ações que pudessem amenizar as tensões existentes, principalmente em relação às medidas administrativas tomadas para evitar a expansão sociodemográfica do local.

\section{O curso de agentes comunitários em saúde}

As ações educativas voltadas para os moradores da CJM integram o Plano Diretor Urbanístico da Fiocruz (PDU) (Brasil, 2005), que passou a orientar a política institucional após a desativação da antiga estrutura. O plano estabeleceu como missão promover no campus de Jacarepaguá a defesa do meio ambiente e da saúde pública, por meio do mapeamento da biodiversidade e controle das doenças. As diretrizes seguem três linhas de ação: pesquisa e difusão do conhecimento; integração à cidade; e planejamento urbanístico e equacionamento dos problemas ocupacionais. Esta estratégia teve por finalidade assegurar que as medidas implementadas fossem pensadas como objeto de ações educativas e mantivessem na localidade um corpo funcional e técnico com capacidade de diálogo com a população. O curso de formação contribuiria nessa direção, ao propor uma capacitação, para os moradores, em termos de controle sobre os fatores socioambientais e biológicos, determinantes dos agravos à saúde, sem perder de vista os interesses e as condições socioeconômicas dos habitantes do lugar.

Em um contexto de ruptura com o esquema anterior, o processo de implantação das ações educativas em saúde envolveu discussões com as lideranças locais, conforme a metodologia da pesquisa-ação (Thiollent, 1985), delineada no projeto Construção de Metodologias Participativas Inovadoras para a Promoção da Saúde, referido na introdução. Esse processo pode ser ilustrado pelo atendimento de grande parte das reivindicações dos moradores em incorporar ao curso temas relativos às doenças parasitárias (pediculose, leishmaniose e parasitoses) e ao meio ambiente (educação ambiental, monitoramento participativo da água). No decorrer das negociações, por sugestão dos jovens, foi inserido um módulo sobre doenças sexualmente transmissíveis (DST) e gravidez e sexualidade. No formato final do curso foram definidos 
os seguintes módulos: 1) Parasitoses intestinais; 2) Construção de mapas participativos; 3) Qualidade da água de rios e boas práticas de manejo; 4) Educação ambiental; 5) Ixodidiose e pediculose; 6) Leishmaniose tegumentar; 7) Saúde sexual e reprodutiva: refletindo sobre saúde e prevenção. Foram disponibilizadas 30 vagas para moradores, selecionados em conjunto com representantes das associações de moradores das comunidades, não sendo determinada uma idade mínima ou máxima, grau de escolaridade ou sexo para ingresso no curso.

O curso procurou seguir os princípios declarados no ideário da Promoção da Saúde, que vinculam as propostas de educação em saúde a ações voltadas para a diminuição da desigualdade, por meio da mobilização da população-alvo para a conquista dos direitos de cidadania (Buss, 2005). O ponto de partida era desenvolver uma metodologia tendo por base as experiências e as práticas dos sujeitos envolvidos. Em parte, isso foi viabilizado pelos encontros entre alguns professores do curso e os líderes comunitários, ocasião em que se procurou levantar as expectativas dos sujeitos e incorporar suas demandas. A esse respeito é fundamental ressaltar os vínculos estabelecidos entre educadores e educandos na fase preliminar do projeto, que estimularam o desenvolvimento da participação comunitária. Por meio da tentativa da construção compartilhada do conhecimento, buscou-se ultrapassar os limites de propostas educativas fundadas em uma abordagem técnica e instrumental, dissociada do contexto sociocultural do público ao qual a ação foi dirigida.

O estreitamento dos laços entre pesquisadores da Fiocruz e os moradores que realizavam trabalhos comunitários foi importante para a consolidação das metas do curso relativas à promoção do conhecimento sobre saúde e ambiente e ao incentivo às ações de controle. Nesse sentido, foi previsto que o agente formado pelo curso atuaria em campanhas educativas, consideradas prioritárias em termos de saúde pública, bem como no encaminhamento de pessoas adoentadas aos serviços adequados dentro e fora da instituição. Ele poderia exercer atividades educativas intersetoriais e prestar orientações às famílias, aproximando-se das competências dos ACS, atribuídas pelo Ministério da Saúde, em relação ao desenvolvimento de atividades de vigilância e promoção da saúde (Brasil, 2000).

Uma característica relevante desse tipo de atuação está no fato de o agente de saúde pertencer às comunidades. Esse pertencimento pressupõe uma familiaridade com as questões locais, o que tenderia a favorecer a conquista da confiança dos moradores pelos ACS para o compartilhamento de seus problemas, além de resultar no fortalecimento do papel dos agentes como lideranças (Lima e Moura, 2005). Parte-se, assim, do pressuposto que o ACS pode fazer uma ponte entre universos culturais distintos, quais sejam o saber científico e o saber popular (Levy, Matos e Tomita, 2004). 
Tendo por base o contexto e os atores envolvidos na criação e desenvolvimento do curso de agente comunitário em saúde na CJM, o presente trabalho analisa as expectativas pessoais e profissionais dos moradores em relação ao curso e suas percepções sobre os temas tratados.

\section{Etnografia das práticas e as visões dos alunos}

A pesquisa envolveu dois procedimentos metodológicos: observação etnográfica das práticas educativas e comunitárias, visando a compreender os discursos e os significados atribuídos ao curso pelos alunos; e uso de questionários, com perguntas abertas e fechadas, para os participantes do curso sobre motivação, expectativas e aprendizagem de conhecimentos em saúde e ambiente. Não houve a intenção de fazer uma descrição dos fundamentos teórico-metodológicos dos conteúdos pedagógicos ministrados; tal aspecto poderá ser tratado em um futuro trabalho.

As atividades do curso foram realizadas nas dependências de um pavilhão hospitalar desativado, onde as aulas eram semanalmente ministradas. $\mathrm{O}$ trabalho de campo seguiu o calendário proposto pelo coordenador do projeto, em conjunto com os professores. Foram previstos 28 encontros, combinando aulas expositivas e práticas com duração de quatro horas, durante as manhãs de sábado, distribuídas nos seguintes módulos: Pediculose, Leishmaniose, Parasitoses, Saúde sexual e reprodutiva, Meio ambiente, Monitoramento participativo e Mapeamento do solo (GPS), ministrados por pesquisadores da Fiocruz de várias áreas disciplinares (medicina, biologia, ciências sociais e psicologia). A turma foi composta por 24 alunos com preponderância de mulheres, de todas as faixas etárias e escolaridade variada, cujo perfil será apresentado no item seguinte.

O ambiente social do curso era presidido por um tipo de abordagem que estudiosos da educação, como Gohn (2006), definem como sendo do domínio da educação não formal, por articular os conteúdos pedagógicos às necessidades e desafios da vida cotidiana. Essa abordagem é compreendida como complementar à educação formal, sendo desenvolvida em espaços comunitários, como associações de moradores e clubes (Trilla, 1996). A configuração estabelecida nessa linha, portanto, favoreceu a observação de comportamentos e noções sobre saúde, relações de gênero e significados da localidade, bem como estreitou os laços sociais. Foi possível captar a expressão de sentimentos e de preferências dos alunos, esboçada sob forma de comentários, gestos, expressões faciais ou momentos de silêncio ao longo dos encontros.

O acompanhamento era igualmente realizado nas atividades extraclasse, momento em que ocorriam conversas informais enriquecedoras, focalizando 
o cotidiano dos moradores. Com recorrência, a conversa recaía sobre quais seriam os planos da instituição para 'eles'. O fato de uma das pesquisadoras ter sido apresentada pelo coordenador do curso como "uma colega que irá acompanhar e trabalhar junto" não deixou dúvidas quanto a condição de alguém de dentro da instituição, evidenciando os desafios dessa posição. Ademais, a sua participação no módulo de Saúde sexual e reprodutiva, apresentando o tema das relações de gênero, destacou também o papel de professora.

Aos poucos, buscou-se provocar certo afastamento da condição de staff. A alternativa foi permanecer nos fundos da sala para minimizar a identificação com os executores do projeto, sem apagar as vantagens dessa posição de insider (Becker, 1997), ou seja, alguém que possui uma visão de 'dentro' e tenta se distanciar. A interação com os participantes ao término das aulas resultava invariavelmente em convites para participação em algumas festividades locais (eventos familiares e religiosos). As formas lúdicas de sociabilidade foram vistas como eficazes para o estudo aqui delineado, pois evidenciavam diversas significações em torno do lazer, do trabalho e da religiosidade do grupo em questão. A observação das redes, das confraternizações comunitárias, das festas familiares e religiosas, dos ritos ligados às tradições locais e as reuniões de associações foi utilizada como paradigma empírico do estudo. Desse modo foi possível captar de outro ângulo as opiniões e as práticas pertinentes ao curso de agentes e compreender como e até que ponto elas afetavam as formas de negociação dos moradores com as normas institucionais.

A posição dos observadores em campo é amplamente discutida na antropologia, aportando um dos dilemas do ofício etnográfico (DaMatta, 1978; Velho, 1981; Peirano, 1995). Nesse sentido, vale mencionar que alguns marcadores sociais (p. ex., gênero) funcionaram como facilitadores nas incursões nas redes interpessoais. Nas conversas com as mulheres no ambiente doméstico, por exemplo, foi possível aprofundar as discussões e fazer alianças, favorecendo um acesso mais informal às pessoas.

Como citado, a observação participante foi complementada pela utilização de um questionário para os alunos, aplicado após a finalização do curso. Foram distribuídos 24 questionários e devolvidos 18. Neste instrumento, buscou-se identificar a visão dos alunos em relação a três aspectos: avaliação geral do curso no que se refere às expectativas atendidas e sugestões de mudanças; visões sobre os módulos em termos de aprendizagem e motivação; e percepções sobre a metodologia de ensino e uso de recursos didáticos utilizados nas aulas.

Todos os participantes foram informados sobre as finalidades acadêmicas do estudo e a preservação do anonimato e consentiram em participar, de forma facultativa, da pesquisa. Tais procedimentos foram norteados pelas normas que regulamentam a pesquisa com seres humanos no Brasil (resolução n. ${ }^{\circ}$ 196/96 do Conselho Nacional de Saúde). 


\section{Perfil dos participantes do curso}

O curso contou com 20 mulheres e quatro homens na faixa etária de 12 a 54 anos, havendo maior concentração na faixa entre 14 a 20 anos. Os alunos serão doravante identificados pelo código: M para masculino e F para feminino, seguido da idade. Muitos já desenvolviam atividades de mobilização comunitária (p. ex., campanhas de prevenção de saúde e do ambiente) e identificaram no curso a possibilidade de adquirir mais conhecimento sobre temas de saúde em geral. A presença dominante das mulheres pode ser compreendida pelas representações sociais da natureza do trabalho em saúde, sobretudo os trabalhos comunitários, por ser uma atividade que envolve o cuidado, atributo normalmente associado ao gênero feminino (Vargas e Romeiro, 1992).

Apenas um terço não possuía o ensino médio. Aqueles com maior escolaridade estavam concentrados entre os mais jovens. Possivelmente a ampliação do acesso à educação pública tem favorecido as novas gerações. Segundo Sposito (2005), a partir da década de 1990, houve um importante crescimento do acesso à escola da população juvenil brasileira. Todavia, esse aumento não tem garantido a entrada no mundo do trabalho e tampouco uma formação de boa qualidade.

Em relação à ocupação, das 20 mulheres, cerca de um terço estava estudando e apenas quatro inseridas no mercado formal. As demais informaram atuar como 'donas de casa' ou em atividades informais. Dos quatro homens, dois estavam empregados e dois eram estudantes. Verificou-se que, em geral, havia um interesse dos participantes em conseguir um emprego próximo à residência e vinculado a uma instituição federal.

\section{Expectativas, sugestões e críticas}

A análise das expectativas e críticas em relação ao curso teve por base as respostas dos alunos sobre o crescimento pessoal, a aplicação prática e o aprimoramento profissional.

A maioria (14/18) indicou que o curso atendeu plenamente às suas expectativas em relação ao crescimento pessoal. Os alunos se referiram tanto ao impacto individual do conjunto de saberes assimilados quanto à aplicação do aprendizado na comunidade. As falas são ilustrativas:

Saber nunca é demais; através do curso poderei compartilhar com pessoas meu conhecimento. Ele também poderá ser útil no futuro (F, 18).

Ajudou-me numa conquista profissional, trouxe autoestima, podendo, através do aprendizado, melhorar a qualidade de vida da comunidade (F, 22). 
A despeito de a avaliação geral ter sido positiva, mais da metade (11/18) registrou que o curso não atendeu às suas expectativas em relação a capacitação profissional e inserção no mercado de trabalho. Um dos obstáculos à profissionalização dos alunos foi a impossibilidade de o curso oferecer um certificado oficial de agente comunitário. A certificação desse tipo de trabalhador é feita pela secretaria municipal de saúde (Lima e Moura, 2005). Para tanto, caberia a realização de contatos com os órgãos responsáveis para validação do curso, o que não ocorreu em função de entraves políticos e administrativos.

A expectativa dos alunos de ingressarem na instituição também foi registrada durante as observações de campo. Implícita ou explicitamente, o tema do 'emprego' vinha à tona nos encontros, principalmente após o encerramento das atividades, indicando que o ingresso no curso, muitas vezes, foi idealizado como uma porta de entrada para a instituição. Embora na proposta do curso não constasse que a instituição concederia estágios ou qualquer forma de vínculo institucional aos participantes, nas conversas mais informais eram mencionadas preocupações com o trabalho e com a renda própria ou dos filhos. Compreende-se que num contexto de precarização e desregulamentação das relações de produção, o emprego público é visto com uma das últimas trincheiras do trabalho 'fordista' (Castells, 1999) por ser um trabalho estável com direitos sociais garantidos.

Em relação às sugestões, algumas alunas, que não trabalhavam fora, propuseram que as aulas não fossem dadas aos sábados. Uma parte minoritária se queixou do comportamento de alguns adolescentes que prejudicavam o bom andamento das aulas com 'brincadeiras fora de hora'. A intensa familiaridade entre os frequentadores, parentes ou vizinhos, promovia uma atmosfera informal durante as aulas. Em outras palavras, a heterogeneidade da turma em termos etários contribuiu para gerar algumas tensões. As críticas feitas à coordenação do curso tiveram por base as lacunas deixadas pela falta de um acompanhamento sistemático ao longo do desenvolvimento dos módulos, bem como pela ausência de apostilas, uniformes e outros materiais, como exemplificado na seguinte fala: "Ficamos muito tempo sem saber o que houve, esperando o professor aparecer para dar uma resposta ao que nós ficávamos perguntando. Blusa, apostila etc." (F, 24).

Outra lacuna apontada se refere à indisponibilidade de recursos e material didático para trabalhos e campanhas de promoção da saúde, dentro da comunidade e em escolas da região, onde os participantes do curso eram chamados para dar palestras de forma voluntária ou atuarem como fiscais do meio ambiente. A falta desses recursos não prejudicou a atuação comunitária. Mesmo sem o material didático ou alguma forma de remuneração, as pessoas continuaram a trabalhar ativamente em suas localidades. A possibilidade de ser um agente comunitário foi encarada por alguns moradores 
como um modo de conservar a natureza e preservar a qualidade de vida daquele espaço, como ilustra o comentário:

Se eu tivesse mais condições, faria cartilhas explicativas e entregaria na comunidade, sempre explicando os assuntos mais polêmicos e conscientizando as pessoas. O que adianta morarmos numa casa imensa, confortável, e termos uma vala ao lado, correndo esgoto a céu aberto. (...). O que adianta também olharmos para toda essa natureza bela e esplêndida e não podermos morar dignamente. Também não temos qualidade de vida. Acho que adianta sim conscientizar os moradores da importância da qualidade de vida e termos a liberdade com responsabilidade de vivermos decentemente num local em que o ser humano também tem que fazer parte do meio ambiente (F, 43).

\section{Visão sobre os módulos}

Os módulos que despertaram maior interesse foram aqueles ligados às doenças endêmicas na região, a saber, Pediculose, Parasitoses e Leishmaniose (Coura, 2005). Por fazerem parte da realidade local, a experiência dos alunos com essas enfermidades foi um aspecto que contribuiu para o envolvimento afetivo e cognitivo com os módulos. Pode ser dito que esses módulos mobilizaram positivamente o grupo, sobretudo por conta do atendimento às reivindicações dos moradores nas negociações para o desenvolvimento das atividades educativas na Colônia. O tema das parasitoses intestinais, por exemplo, já vinha sendo estudado por pesquisadores da Fiocruz, interessados em realizar um diagnóstico parasitológico para a prevenção e controle das verminoses na localidade.

Interessante notar que alguns assuntos abordados promoveram retraimento dos alunos no âmbito de sua participação nas aulas em função das imagens projetadas sobre sintomas ou sinais corporais, incluindo mudanças físicas, como manchas escuras na pele, provocados pelos agravos citados. Em uma das aulas sobre pediculose, por exemplo, quando o professor mostrou imagens de casos graves de pessoas infestadas pelo inseto, foi observado o desconforto geral que o assunto despertava nos alunos. Após os esclarecimentos sobre os equívocos e 'mitos' referentes à moléstia, uma aluna (mãe e avó) revelou ter aplicado inseticida na cabeça do filho por desconhecer os danos à saúde. Além disso, muitas mulheres descreveram que seus cabelos foram cortados rentes ao couro cabeludo ou que foram obrigadas a cobrir a cabeça com lenço branco, sendo alvo de discriminação. A partir dos depoimentos dos alunos foi promovido um debate com a turma sobre experiências desconfortáveis relacionadas à crença de que o piolho estaria ligado, primordialmente, à falta de higiene pessoal, revelando o estigma da doença. 
No caso do módulo sobre leishmaniose, cabe ressaltar que esta é uma doença endêmica no local; assim, quase todos conheciam pessoas adoentadas, incluindo vizinhos e familiares. Tal fato contribuiu para explicar o constrangimento dos alunos quando os professores sugeriram que eles visitassem as casas da comunidade para identificar se os animais domésticos, sobretudo os cães, estavam infectados. Pelo fato de ser uma infecção zoonótica, os cães são considerados os principais reservatórios domésticos da doença nos grandes centros urbanos. Em caso de infecção, as residências seriam notificadas e, dependendo do grau da doença, o animal poderia ser sacrificado.

Esse tipo de constrangimento foi também percebido em relação às parasitoses intestinais, quando os alunos foram convidados a recolher fezes para exames laboratoriais a fim de detectar a presença de eventuais parasitos. Nesse caso, havia o temor de uma publicização dos resultados sobre verminoses, principalmente entre os mais jovens: “Ah, não vou fazer não; depois, se eu tiver com verme, as meninas vão ficar zoando" (F, 14). Tal panorama, entretanto, parece não ter impedido o aprendizado dos conteúdos dados nos módulos, como sugere a fala sobre o tema:

Pra mim foi um módulo superprático e objetivo, muito bem explicado. O vídeo me ajudou bastante. Toda semana tinha novidade em cima do tema, dando oportunidades de mostrar o que nós aprendemos na teoria e prática. Além disso, foi passado ao longo do módulo o que deveríamos saber no outro, no que diz respeito ao sintoma e como evitar. Trocamos ideias bem-sucedidas (M, 20).

Apesar das narrativas dos sujeitos evocarem sentimentos de medo e preocupação com as enfermidades, a proximidade com as doenças citadas parece ter favorecido uma sensibilização para que os alunos revelassem práticas inadequadas ou métodos tradicionalmente preconizados para o tratamento. Ademais, alguns depoimentos sugerem que a abordagem adotada (slides, fotos, trabalhos em campo) promoveu novos saberes diante dos agravos, como indica a fala a seguir: “O medo da população com essa doença [leishmaniose] fez com que o interesse fosse maior, a maneira direta e explicativa nos deu segurança de como nos prevenirmos e agora vemos com clareza onde está o perigo" (F, 24).

O módulo sobre saúde sexual e reprodutiva, por sua vez, se destacou dentre as expectativas iniciais, em função da maneira com que o tema foi tratado: aulas expositivas, seguidas da dramatização de situações, envolvendo o manuseio de preservativos e da utilização de jogos educativos. As falas são ilustrativas:

Foi ótimo. O grupo sempre trabalhando junto sem vergonhas. Apesar do tema, a professora deixou todo mundo bem à vontade mostrando toda experiência como médica e respeitando os tabus (F, 24). 
Pra mim, um módulo fantástico [SSR], pois envolve a doença e a vida afetiva. E aprender a se prevenir para não contrair uma doença ou uma gravidez indesejada e com isso ter prazer total (F, 20).

Cabe ressaltar que durante esse módulo foi observado o desconforto dos alunos quando foram exibidos cartazes das doenças sexualmente transmissíveis já em fase avançada. Por se tratar de um grupo heterogêneo na idade, mas homogêneo em parentesco e vizinhança, a visualização de órgãos sexuais danificados pelas doenças gerou certo incômodo. A configuração do grupo foi um complicador na hora de os mais jovens se posicionarem diante de assuntos relacionados a sexualidade, gravidez e aborto. No entanto, na visão da maioria dos alunos, o tema foi bem conduzido, promovendo um aprendizado e um espaço para um diálogo sobre temas tabus. A importância de uma abordagem dialógica tem sido objeto de reflexões sobre as ações educativas relativas à saúde sexual e reprodutiva (Monteiro, 2002; Moraes, 2004).

$\mathrm{O}$ módulo sobre meio ambiente reiterou o interesse da comunidade pela preservação ambiental e valorização das condições de vida local. Nesse módulo, foi destacado o uso diversificado de recursos didáticos, como aulas extraclasse, passeios a museu, vídeo e palestras: "Eu adorei, teve visita ao museu, pude mexer e conhecer as plantas. Pra mim, que quero ser bióloga, foi ótimo" (F, 15).

$\mathrm{Na}$ avaliação geral dos alunos, os módulos que tratavam de monitoramento da água e mapeamento do solo poderiam ter sido mais explorados, e os processos de ensino e aprendizagem em sala, revistos. No módulo Mapeamento do solo foi utilizado um aparelho de navegação (GPS), conhecido como um sistema de posicionamento global, orientado por satélites. Segundo os participantes, os recursos utilizados dificultaram a aprendizagem: “Muita teoria, muito falada e cansativa e não consegui entender algumas coisas, o porquê do mapa etc." (F, 24)

Tal dificuldade possivelmente decorre do fato de o conteúdo exigir um conhecimento específico de matemática, que muitos alunos não possuíam. Como o curso não exigiu uma escolaridade mínima dos participantes, alguns apresentavam lacunas na formação educacional. Dessa forma, apesar de manusear o aparelho, boa parte das pessoas não conseguiu assimilar sua leitura, o que provocou o desinteresse e ausências durante quase todo o módulo. Nesse contexto, ganhou força no grupo a narrativa da eficácia da lógica local, traduzida pelo reconhecimento do espaço, o saber prático, em detrimento do saber formal. As pessoas estabeleceram nomenclaturas e códigos próprios para se referirem a ruas e lugares na Colônia, como, por exemplo, 'rua de cima', 'rua de baixo', 'rua da lixeira', os quais foram questionados pelos técnicos, comprometendo o processo de aprendizagem. Essa situação remete à importância de os educadores levarem em conta as experiências e saberes 
dos educandos, buscando estabelecer um diálogo entre os conhecimentos local e científico nos espaços de ensino, formais ou não formais.

No que diz respeito à metodologia de ensino dos módulos, as avaliações indicaram aspectos positivos como 'envolvimento afetivo', 'linguagem clara e acessível', 'variedade de material', 'aulas participativas e práticas' e 'troca de experiências'. Tais elementos foram considerados fundamentais para o bom andamento de um curso voltado à capacitação dentro de uma comunidade. De um modo geral, a capacidade comunicativa dos professores foi notada pelo conjunto dos participantes, como expressa a fala a seguir: "Todos os professores explicam muito bem e atendem a todos os alunos" (F,15).

Contudo, grande parte dos alunos mencionou dificuldade em interagir com professores aos quais denominavam 'mais sérios' ou que não conseguiam se 'entrosar' com o grupo, principalmente nos módulos considerados mais 'difíceis', que envolviam saberes específicos, como já citado. A crítica dos alunos quanto ao acentuado formalismo dos professores, interligado à inteligibilidade do conteúdo do módulo, sugere a importância da relação educador-educando no processo ensino-aprendizagem, sobretudo no ensino não formal.

Em suma, os alunos assinalaram que a confiança e os laços estabelecidos com os professores em alguns módulos favoreceram o interesse e a aprendizagem dos temas, reiterando que a forma como o professor se apresenta e interage com a turma é fundamental para o estímulo e o desempenho dos alunos. Trata-se de uma posição defendida, tanto no campo da educação formal como no não formal, por estudiosos importantes como Paulo Freire (1977). Desde os anos 1970, o autor preconizava o desenvolvimento de metodologias participativas na educação. Ou seja, um novo conhecimento elaborado a partir da incorporação de diferentes visões de mundo e saberes no esforço de fazer confluir o saber formal, representado pelos pesquisadores-professores e o saber informal dos alunos. Nesta direção, Gadotti (1999) afirma que a ação educativa fica comprometida se não houver uma mudança na postura do professor, como 'detentor de saberes' para 'facilitador da aprendizagem'. O educador deve buscar compreender a realidade de seus alunos e a valorizar seus saberes, tornando o clima propício ao desenvolvimento de potencialidades educativas.

Nessa linha de raciocínio, Gohn (2006) argumenta que "quando uma pessoa é aceita e compreendida, devolve os mesmos sentimentos com o grupo que a acolheu". Para a autora, isto implica a entrada no campo do simbólico, das orientações e representações que conferem sentido e significado às ações humanas. Demais autores enfatizam a importância da perspectiva dialógica e participativa no processo de aprendizagem de conteúdos diversos, capazes de estimular mudanças nas práticas sociais e em saúde (Gazzinelli, 2005; Bourdieu, 1996). 


\section{Considerações finais}

A análise do curso de formação dos agentes comunitários foi realizada através da integração de vários procedimentos que ajudaram a compor o mosaico interpretativo. O trabalho de campo etnográfico sobre as práticas educativas e comunitárias favoreceu a compreensão do processo de construção e desenvolvimento da proposta educativa em um espaço de ensino não formal, contemplando a visão dos diversos atores envolvidos. Foi possível caracterizar o cenário político-institucional que resultou na criação do curso, bem como identificar as regras e códigos sociais que presidem os usos contemporâneos do espaço da Colônia Juliano Moreira. Os dados dos questionários dos alunos, por sua vez, permitiram complementar as observações das práticas comunitárias e educativas.

Consideramos que a metodologia participativa, adotada no processo de formulação do curso envolvendo os moradores da comunidade e os novos representantes institucionais na definição dos conteúdos dos módulos, facilitou não só o bom andamento do projeto, mas o aprendizado e a participação dos alunos. Os dados sugerem que o curso promoveu conhecimento e estimulou práticas educativas (individuais e coletivas) em ambiente e saúde, expressas por convites aos alunos para realização de palestras em escolas e de atividades de fiscalização ambiental na região. Tais iniciativas, somadas aos relatos sobre a contribuição do curso para o crescimento pessoal e estreitamento dos laços comunitários, indicam que houve um fortalecimento das redes comunitárias locais e do capital social de alguns participantes (Bourdieu, 1996).

Cabe ressaltar, no entanto, que o curso não atendeu às demandas relativas à atuação profissional, na própria instituição promotora do curso ou no mercado de trabalho em geral. Uma das razões foi a impossibilidade da instituição em emitir certificação que lhes conferisse competência para atuar como agentes comunitários de saúde em outros contextos. O caráter pontual dos projetos sociais e a precária oferta de empregos no Brasil permitem compreender que a participação em um curso promovido por uma entidade federal seja percebida como uma possibilidade de inserção em um emprego formal. Tal aspecto sugere a pertinência de os idealizadores da proposta educativa explicitarem os limites e possibilidades de suas ações junto ao público.

A despeito do reconhecimento dos resultados obtidos, as transformações precisam ser pensadas do ponto de vista estrutural, evitando uma interpretação reducionista dos direitos de saúde e cidadania. Acreditamos, porém, que os projetos sociais, ainda que sejam ações limitadas, podem oferecer novas oportunidades de profissionalização e trabalho, contribuindo para o aumento de perspectivas de futuro para os indivíduos (Monteiro e Cecchetto, 2006).

Os estudos etnográficos que analisam a construção e as repercussões dos diferentes tipos de intervenções sociais articuladas ao contexto e aos 
aspectos culturais da população ainda são escassos. Neste sentido, esse trabalho pretende colaborar para uma antropologia das ações educativas, desenvolvida em espaços formais e não formais, que leve em conta a polifonia dos atores, discursos e práticas.

\section{Agradecimentos}

Agradecemos aos pesquisadores do Instituto Oswaldo Cruz Evelyse Lemos, Júlio Barbosa e Marisa Soares pelas valiosas observações.

\section{Notas}

1 Pesquisadora do Laboratório de Educação em Ambiente e Saúde do Instituto Oswaldo Cruz, Fundação Oswaldo Cruz (IOC/Fiocruz), Rio de Janeiro, Brasil. Doutora em Saúde Coletiva pela Universidade do Estado do Rio de Janeiro (Uerj). <face@ioc.fiocruz.br> Correspondência: Laboratório de Educação em Ambiente e Saúde, Instituto Oswaldo Cruz, Fundação Oswaldo Cruz, Av. Brasil, 4.365, CEP 21045-900, Manguinhos, Rio de Janeiro, Brasil.

2 Pesquisadora do Laboratório de Educação em Ambiente e Saúde do Instituto Oswaldo Cruz, Fundação Oswaldo Cruz (IOC/Fiocruz), Rio de Janeiro, Brasil. Doutora em Saúde Pública pela Fundação Oswaldo Cruz. <msimone@ioc.fiocruz.br>

3 Bolsista do Laboratório de Educação em Ambiente e Saúde do Instituto Oswaldo Cruz, Fundação Oswaldo Cruz (IOC/Fiocruz), Rio de Janeiro, Brasil. Bacharel em Ciências Sociais Universidade Federal Fluminense (UFF) <ericafernandes@terra.com.br> 


\section{Referências}

ANDRE, Marly. Etnografia da prática escolar. 13. ed. Campinas: Papirus, 2007.

BARBOSA, Julio Vianna. Construção de metodologias participativas em saúde da comunidade no campus da Fiocruz-Jacarepaguá na zona oeste do Rio de Janeiro. Fundação Oswaldo Cruz, Edital PDTSP-SUS, PepsiIOC 01, 2004.

BAUMAN, Zigmunt. Comunidade: a busca por segurança no mundo atual. Rio de Janeiro: Jorge Zahar Editores, 2003.

BECKER, Howard. Uma teoria da ação coletiva. Rio de Janeiro: Zahar Editores, 1977.

BOSI, Maria Luiza; MERCADO, Franciso (Org.). Avaliação qualitativa de programas de saúde, enfoques emergentes. Petrópolis: Vozes, 2006.

BOURDIEU, Pierre. Razões práticas: sobre a teoria da ação. Campinas: Papirus, 1996.

BRASIL. Ministério da Saúde, Fundação Oswaldo Cruz. Campus Jacarepaguá: fronteiras entre ciência e natureza. Rio de Janeiro: Fiocruz, 2005.

Ministério da Saúde. Secretaria de Políticas de Saúde. Projeto de promoção da saúde: as cartas de promoção da saúde. Brasília: Ministério da Saúde, 2002.

BUSS, Paulo. Promoção da saúde e qualidade de vida. Ciência \& Saúde Coletiva, Rio de Janeiro, v. 5, n. 1, p. 163-77, 2000.

CASTELLS, Manuel. A sociedade em rede. São Paulo: Paz e Terra, 1999.

COURA, José Rodrigues (Org.). Dinâmica das doenças infecciosas e parasitárias. Rio de Janeiro: Guanabara Koogan, v. 2, 2005.

DAMATTA, Roberto. Ofício do etnólogo ou como ter anthropological blues. In: NUNES, Edson (Org.). Aventura sociológica. Rio de Janeiro: Zahar Editores, 1978. p. 23-35.
DUARTE, Luiz Fernando et al. Vicissitudes e limites da conversão à cidadania nas classes populares brasileiras. Revista Brasileira de Ciências Sociais, São Paulo, v. 8, n. 22, p. 5-19, 1993.

FREIRE, Paulo. Pedagogia do oprimido. Rio de Janeiro: Paz e Terra, 1977.

FUNDAÇÃO OSWALDO CRUZ. Campus de Jacarepaguá 1 : fronteiras entre ciência e natureza. Rio de Janeiro: Fundação Oswaldo Cruz, Presidência, 2005.

GADOTTI, Moacir. Convite à leitura de Paulo Freire. São Paulo: Scipione, 1999.

GAZZINELLI, Maria Flavia. Educação em saúde: conhecimentos, representações sociais e experiências da doença. Cadernos de Saúde Pública, Rio de Janeiro, v. 21, n. 1, p. 200-206, 2005.

GOHN, Maria Gloria. Educação não-formal, participação da sociedade civil e estrutura colegiada nas escolas. Ensaio: Avaliação e Políticas Públicas em Educação, v. 14, n. 50, p. 27-38, jan./mar., 2006.

ISER (Instituto de Estudos da Religião); FUNDAÇÃO OSWALDO CRUZ. Convênio 102/2003. Estudo das famílias moradoras no campus de Jacarepaguá: diagnóstico e alternativas de ação. Relatório preliminar. Rio de Janeiro, 2004. Mimeografado.

LEVY, Flavia Mauad; MATOS, Patrícia de Sousa; TOMITA, Nilce. Programa de agentes comunitários de saúde: a percepção de usuários e trabalhadores da saúde. Cadernos de Saúde Pública, Rio de Janeiro, v. 20, n. 1, p. 197-203, jan./fev., 2004

LIMA, Jacob; MOURA, Maria do Carmo. Trabalho atípico e capital social: os agentes comunitários de saúde na Paraíba. Sociedade e Estado, Brasília, v. 20, n. 1, p. 103-133, jan./abr., 2005.

MINAYO, Maria Cecília. Avaliação por Triangulação de Métodos: abordagem de 
programas sociais. Rio de Janeiro: Editora Fiocruz, 2005.

MONTEIRO, Simone; CECCHETTO, Fátima. Trayectorias juveniles e intervenciones sociales: repercusiones en las practicas sociales y em salud. Cadernos de Saúde Pública, Rio de Janeiro, v. 22, n. 1, p. 193-200, 2006.

MONTEIRO, Simone. Qual prevenção?: Aids, gênero e sexualidade em uma favela carioca. Rio de Janeiro: Editora Fiocruz, 2002.

MORAES, Danielle. Aids, saúde reprodutiva e prevenção: estudo de caso sobre práticas educativas em uma ONG, Rio de Janeiro, Brasil. Dissertação (Mestrado em Saúde Pública) - Escola Nacional de Saúde Pública, Fundação Oswaldo Cruz, Rio de Janeiro, 2004.

NOVAES, Regina. Juventudes cariocas: mediações, conflitos e encontros culturais. In: VIANNA H. (Org.). Galeras cariocas: territórios de conflito e encontros culturais. Rio de Janeiro: Editora UFRJ, 1997. p. 119-160.

PEIRANO, Mariza. A favor da etnografia. Rio de Janeiro: Relume Dumará, 1995.
SPOSITO, Marilia Pontes. Algumas reflexões e muitas indagações sobre as relações entre juventude e escola no Brasil. In: ABRAMO, Helena; BRANCO, Pedro Paulo Martoni (Org.). Retratos da juventude brasileira: análise de uma pesquisa nacional. São Paulo: Fundação Perseu Abramo, 2005. p. 87-127.

THIOLLENT, Michel. Metodologia da pesquisa-ação. São Paulo: Cortez; Autores Associados, 1985.

TRILLA, Jaume. La educación fuera de la escuela: ámbitos no formales y educación social. Barcelona: Ariel, 1996.

VARGAS, Eliane; ROMEIRO, Elizabeth (Org.). Práticas de educação em saúde: programa de assistência integral à saúde da mulher. Rio de Janeiro: Ensp, 1992.

VELHO, Gilberto. Desvio e divergência. Rio de Janeiro: Zahar, 1981.

ZALUAR, Alba. Cidadãos não vão ao paraíso. São Paulo: Escuta; Campinas: Unicamp, 1994.

Recebido em 10/02/2010

Aprovado em 24/05/2010 
